\title{
Development of a method for the synthesis of 2,4,5- trisubstituted oxazoles composed of carboxylic acid, amino acid, and boronic acid
}

\author{
Kohei Yamada, Naoto Kamimura and Munetaka Kunishima*
}

\author{
Full Research Paper \\ Address: \\ Faculty of Pharmaceutical Sciences, Institute of Medical, \\ Pharmaceutical, and Health Sciences, Kanazawa University, \\ Kakuma-machi, Kanazawa 920-1192, Japan \\ Email: \\ Munetaka Kunishima* - kunisima@p.kanazawa-u.ac.jp \\ * Corresponding author \\ Keywords: \\ one-pot oxazole synthesis; Suzuki-Miyaura coupling; triazine; \\ 5-(triazinyloxy)oxazole; trisubstituted oxazole
}

\author{
Beilstein J. Org. Chem. 2017, 13, 1478-1485. \\ doi:10.3762/bjoc.13.146
}

Received: 07 April 2017

Accepted: 10 July 2017

Published: 27 July 2017

Associate Editor: T. J. J. Müller

(c) 2017 Yamada et al.; licensee Beilstein-Institut.

License and terms: see end of document.

\begin{abstract}
A novel method for the synthesis of trisubstituted oxazoles via a one-pot oxazole synthesis/Suzuki-Miyaura coupling sequence has been developed. One-pot formation of 5-(triazinyloxy)oxazoles using carboxylic acids, amino acids and a dehydrative condensing reagent, DMT-MM, followed by Ni-catalyzed Suzuki-Miyaura coupling with boronic acids provided the corresponding 2,4,5trisubstituted oxazoles in good yields.
\end{abstract}

\section{Introduction}

Oxazoles are found in numerous natural products and are used as a broad range of artificial compounds [1,2]. In particular, 2,4,5-trisubstituted oxazoles attract attention as pharmacologically potent scaffolds because structural diversity can be efficiently generated by the introduction of a variety of substituents. Accordingly, numerous synthetic methods have been developed and can be roughly classified into three synthetic strategies (Scheme 1a).

i) The cyclization method: many methods, such as the Robinson-Gabriel oxazole synthesis using $\alpha$-acylaminoketone $[3,4]$, the Davidson oxazole synthesis with $\alpha$-acyloxyketone [5], and modifications of these [6,7], have been developed. Moreover, cycloaddition of two starting materials, such as $\alpha$-haloketones and primary amides [8], alkynes and nitriles [9], amines and $\alpha, \beta$-unsaturated carbonyl compounds [10], etc. [11] have been reported. However, these reactions are often conducted under harsh reaction conditions and multistep syntheses of the starting materials are needed. ii) The functionalization method: various regioselective metalations and subsequent functionalizations of the oxazole core skeleton using $\mathrm{Cu}$ [12], $\mathrm{Pd}$ [13], $\mathrm{Mg}$ [14], Zn [14], etc. [15] have been developed. This linear synthetic approach inevitably requires multistep processes and often needs prehalogenation [16]. iii) The multicomponent method: 


\section{a) previous work}<smiles>[R]Cc1nc(CCP)c(CCP)o1</smiles><smiles>[R]c1nc([R2])c([R])o1</smiles>

iii) multicomponent

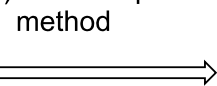

ii) functionalization method

$$
\begin{gathered}
R^{1} X^{\prime}-Z^{-R^{3}} \\
1-Y^{\prime} \\
R^{2}
\end{gathered}
$$

b) this work

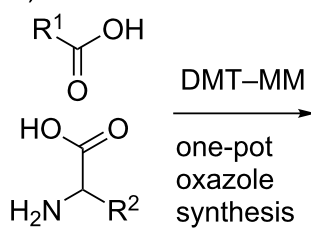

$$
\begin{aligned}
& \mathrm{HO}_{\mathrm{B}^{-}}-\mathrm{R}^{3} \\
& \mathrm{OH} \\
& \text { Suzuki- } \\
& \text { Miyaura } \\
& \text { coupling }
\end{aligned}
$$<smiles>[R]c1nc([R])c([R])o1</smiles>

trisubstituted oxazole

Scheme 1: Our strategy for the concise synthesis of 2,4,5-trisubstituted oxazoles.

only two strategies have been reported to the best of our knowledge. One is a combination of the Ugi reaction, which uses 2,4dimethoxybenzylamine, arylglyoxal, carboxylic acid, and isonitrile as components, and a subsequent Robinson-Gabriel reaction [17]. The other is an Au-catalyzed tandem oxazole synthesis using a primary amide, aldehyde, and alkyne [18]. These methods are reasonable for the synthesis of diverse libraries of trisubstituted oxazoles because the combination of three starting materials that are corresponding to the substituents can be readily altered. However, these reactions require strongly acidic conditions or high temperatures. Therefore, a mild method for the synthesis of diverse trisubstituted oxazoles using three commercially available compounds with a wide variety of structures is still desired.

Previously, we reported a one-pot synthesis of oxazolone from carboxylic acids and amino acids using a dehydrative condensing reagent, 4-(4,6-dimethoxy-1,3,5-triazin-2-yl)-4methylmorpholinium chloride (DMT-MM [19-22])[23]. Formation of 5-(triazinyloxy)oxazole is also reported to occur when an excess of DMT-MM was used. Recently, Jin and co-workers reported that Ni-catalyzed Suzuki-Miyaura coupling between triazinyloxybenzene and arylboronic acids affords the corresponding biaryl compounds [24-33]. In this context, we envisioned application of this Suzuki-Miyaura coupling to a 5-(triazinyloxy)oxazole would provide trisubstituted oxazoles (Scheme 1b). Since many kinds of carboxylic acids, amino acids and boronic acids, which are corresponding to 2-, 4-, and 5 -substituents of the oxazole, respectively, are commercially available, this method is suitable for the synthesis of a diverse variety of trisubstituted oxazoles. Herein, we described an efficient method for the synthesis of trisubstituted oxazoles through a one-pot oxazole synthesis and subsequent Suzuki-Miyaura coupling.

\section{Results and Discussion}

The study was initiated with the preparation of the key intermediate, 5-(triazinyloxy)oxazole $\mathbf{3}$, from carboxylic acid $\mathbf{1}$ and amino acid 2 under conditions improved from [23] (Table 1). A one-pot sequence involving formation of an activated ester from benzoic acid (1a) with DMT-MM, $N$-benzoylation of alanine (2a), cyclodehydration, and introduction of the triazinyl group was conducted in 1,4-dioxane $/ \mathrm{H}_{2} \mathrm{O}$ to give the desired 5-(triazinyloxy)oxazole 3aa in 78\% yield (Table 1, entry 1). A series of carboxylic acids were subjected to the reaction conditions. Aromatic carboxylic acids with both electron-withdrawing and electron-donating groups gave good yields (Table 1, entries 2 and 3). In the case of aliphatic carboxylic acids, 3-phenylpropionic acid (1d) gave a slightly decreased amount of $\mathbf{3 d a}$ in $54 \%$ yield (Table 1 , entry 4 ), whereas the more sterically demanding $\mathbf{1 e}$ gave the desired product $\mathbf{3 e a}$ in a good yield (Table 1, entry 5). The reaction was carried out with different amino acids, resulting in a varied substitution pattern at the 4-position of the oxazole. The one-pot oxazole synthesis with phenylalanine (2b), valine (2c), leucine (2d), methionine (2e), and phenylglycine (2f) proceeded to give the corresponding intermediates in good yields (Table 1, entries 6-10). Despite the existence of highly polar starting materials and relatively more lipophilic activated esters and oxazolone intermediates during the course of the reaction, various 5-(triazinyloxy)oxazoles were uneventfully synthesized under these improved conditions.

According to the procedure previously reported [24], we examined Ni-catalyzed Suzuki-Miyaura coupling between 5-(triazinyloxy)oxazole $3 \mathbf{a a}$ and phenylboronic acid (4a, Table 2). As expected, the desired trisubstituted oxazole 5aaa was obtained in $21 \%$ yield (Table 2 , entry 1 ). The use of different bidentate $(\mathrm{dppp})$ or monodentate $\left(\mathrm{PCy}_{3}\right)$ phosphines as 
Table 1: One-pot synthesis of 5-(triazinyloxy)oxazole under improved conditions
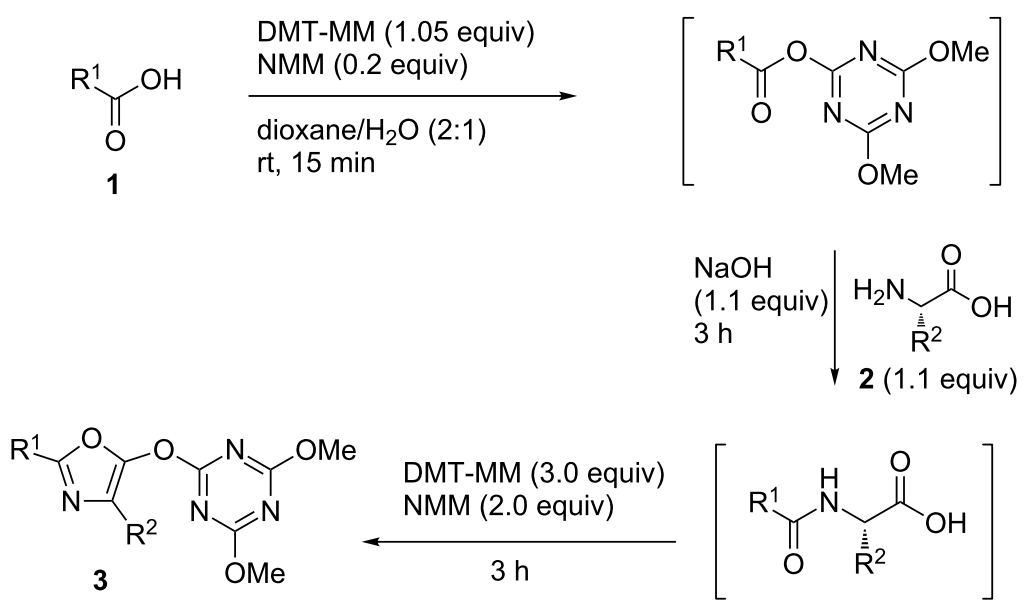

\begin{tabular}{|c|c|c|c|}
\hline entry & carboxylic acid 1 & amino acid 2 & yield of $3(\%)^{a}$ \\
\hline 1 & $1 \mathbf{a}$ & alanine $(\mathbf{2 a})$ & 3aa, 78 \\
\hline 2 & $1 b$ & $2 a$ & 3ba, 69 \\
\hline 3 & 10 & $2 a$ & $3 \mathbf{c a}, 60$ \\
\hline 4 & 1d & $2 a$ & 3da, 54 \\
\hline 5 & $1 e^{0}$ & $2 a$ & 3ea, 71 \\
\hline 6 & $1 a$ & phenylalanine (2b) & $3 a b, 78$ \\
\hline 7 & $1 a$ & valine $(2 c)$ & $3 a c, 83$ \\
\hline 8 & $1 a$ & leucine (2d) & 3ad, 70 \\
\hline 9 & $1 a$ & methionine (2e) & 3ae, 70 \\
\hline 10 & $1 a$ & phenylglycine (2f) & 3af, 78 \\
\hline
\end{tabular}

alsolated yield.

ligands for the $\mathrm{Ni}$ catalyst resulted in poor yields (Table 2, entries 2 and 3). Notably, we found that 3 equiv of $\mathrm{LiCl}$ was an effective additive for shortening the reaction time $(3 \mathrm{~h})$ and improving the yield (73\%, Table 2, entry 4) [34]. Other lithium halides, except for LiF, were also effective (Table 2, entries 5-7). However, utilization of $\mathrm{Na}^{+}$and $\mathrm{K}^{+}$as counter cations for the additive provided inferior results (Table 2, entries 8 and 9). Interestingly, switching the counter cation of the base to $\mathrm{Li}^{+}$did not afford any product (Table 2, entry 10). The reaction with $\mathrm{PdCl}_{2}$ (dppf) instead of $\mathrm{NiCl}_{2}$ (dppf) reduced the outcome of the reaction (Table 2 , entry 11 ). No product was obtained when boronic acid pinacol ester 6 and borate salt 7 were used as a 
Table 2: Screening of reaction conditions of Suzuki-Miyaura coupling with 3aa.

\begin{tabular}{|c|c|c|c|c|c|c|}
\hline \multirow[b]{2}{*}{ entry } & $\overbrace{3 \mathrm{aa}}^{\mathrm{O}}$ & Me & $\begin{array}{c}\mathrm{HO}_{\mathrm{B}^{-}}^{-\mathrm{Ph}} \\
\mathrm{O}_{\mathrm{H}} \\
\text { 4a (4 equiv) }\end{array}$ & $\begin{array}{l}\text { metal cat. (5 mol \%) } \\
\mathrm{K}_{3} \mathrm{PO}_{4}(7 \text { equiv) } \\
\begin{array}{l}\text { solvent } \\
\text { reflux }\end{array}\end{array}$ & \multicolumn{2}{|c|}{$\overbrace{\mathrm{Me}}^{\mathrm{Ph}} \overbrace{\mathrm{N}}^{\mathrm{Oh}}$} \\
\hline & metal cat. & base & additive (3 equiv) & solvent & time $(\mathrm{h})$ & yield of 5 aaa $(\%)^{a}$ \\
\hline 1 & $\mathrm{NiCl}_{2}(\mathrm{dppf})$ & $\mathrm{K}_{3} \mathrm{PO}_{4}$ & - & toluene & 19 & 21 \\
\hline 2 & $\mathrm{NiCl}_{2}(\mathrm{dppp})$ & $\mathrm{K}_{3} \mathrm{PO}_{4}$ & - & toluene & 12 & 9 \\
\hline 3 & $\mathrm{NiCl}_{2}\left(\mathrm{PCy}_{3}\right)_{2}$ & $\mathrm{~K}_{3} \mathrm{PO}_{4}$ & - & toluene & 20 & 12 \\
\hline 4 & $\mathrm{NiCl}_{2}$ (dppf) & $\mathrm{K}_{3} \mathrm{PO}_{4}$ & $\mathrm{LiCl}$ & toluene & 3 & $73(68 \%)^{b}$ \\
\hline 5 & $\mathrm{NiCl}_{2}(\mathrm{dppf})$ & $\mathrm{K}_{3} \mathrm{PO}_{4}$ & $\mathrm{LiF}$ & toluene & 21 & 35 \\
\hline 6 & $\mathrm{NiCl}_{2}$ (dppf) & $\mathrm{K}_{3} \mathrm{PO}_{4}$ & $\mathrm{LiBr}$ & toluene & 3 & 64 \\
\hline 7 & $\mathrm{NiCl}_{2}(\mathrm{dppf})$ & $\mathrm{K}_{3} \mathrm{PO}_{4}$ & Lil & toluene & 3 & 70 \\
\hline 8 & $\mathrm{NiCl}_{2}(\mathrm{dppf})$ & $\mathrm{K}_{3} \mathrm{PO}_{4}$ & Nal & toluene & 24 & 0 \\
\hline 9 & $\mathrm{NiCl}_{2}$ (dppf) & $\mathrm{K}_{3} \mathrm{PO}_{4}$ & $\mathrm{KI}$ & toluene & 17 & 51 \\
\hline 10 & $\mathrm{NiCl}_{2}(\mathrm{dppf})$ & $\mathrm{Li}_{3} \mathrm{PO}_{4}$ & $\mathrm{LiCl}$ & toluene & 26 & 0 \\
\hline 11 & $\mathrm{PdCl}_{2}(\mathrm{dppf}) \cdot \mathrm{CH}_{2} \mathrm{Cl}_{2}$ & $\mathrm{~K}_{3} \mathrm{PO}_{4}$ & $\mathrm{LiCl}$ & toluene & 22 & 0 \\
\hline $12^{c}$ & $\mathrm{NiCl}_{2}(\mathrm{dppf})$ & $\mathrm{K}_{3} \mathrm{PO}_{4}$ & $\mathrm{LiCl}$ & toluene & 20 & 0 \\
\hline $13^{d}$ & $\mathrm{NiCl}_{2}$ (dppf) & - & $\mathrm{LiCl}$ & toluene & 12 & 0 \\
\hline 14 & $\mathrm{NiCl}_{2}$ (dppf) & $\mathrm{K}_{3} \mathrm{PO}_{4}$ & $\mathrm{LiCl}$ & DME & 10 & 0 \\
\hline 15 & $\mathrm{NiCl}_{2}(\mathrm{dppf})$ & $\mathrm{K}_{3} \mathrm{PO}_{4}$ & $\mathrm{LiCl}$ & 1,4-dioxane & 21 & 0 \\
\hline 16 & $\mathrm{NiCl}_{2}(\mathrm{dppf})$ & $\mathrm{K}_{3} \mathrm{PO}_{4}$ & $\mathrm{LiCl}$ & toluene $80^{\circ} \mathrm{C}$ & 23 & 36 \\
\hline 17 & $\mathrm{NiCl}_{2}$ (dppf) & $\mathrm{K}_{3} \mathrm{PO}_{4}$ & $\mathrm{LiCl}$ & toluene $160{ }^{\circ} \mathrm{C}(\mathrm{MW})$ & $20 \min$ & 30 \\
\hline
\end{tabular}

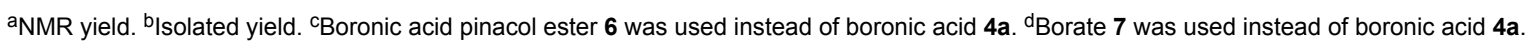<smiles>CC1(C)OB(P)OC1(C)C</smiles>

6

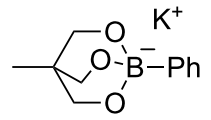

7 coupling partner (Table 2, entries 12 and 13) [35]. Dimethoxyethane (DME) and 1,4-dioxane as ethereal solvents did not improve the yields (Table 2, entries 14 and 15). Decreasing the temperature to $80{ }^{\circ} \mathrm{C}$ or increasing to $160{ }^{\circ} \mathrm{C}$ by microwave irradiation were not effective for improving the reaction (Table 2 , entries 16 and 17). Consequently, we found that the reaction shown in entry 4 afforded the optimal result (see Table S1 in Supporting Information File 1 for further manipulation of the reaction conditions).

A number of trisubstituted oxazoles were synthesized using 5-(triazinyloxy)oxazoles 3 and various boronic acids 4 (Table 3). To our disappointment, the reaction of 3aa with the arylboronic acid possessing an electron-withdrawing group $\mathbf{4 b}$ decreased the yield of $\mathbf{5 a a b}$ ( $25 \%$, Table 3 , entry 1). Further investigation of the reaction conditions revealed that the reaction with additional dppf ( $5 \mathrm{~mol} \%$ ) in a sealed tube increased the yield to $64 \%$ (Table 3 , entry 2 ) [36,37]. These reaction conditions were defined as conditions $\mathrm{B}$, whereas the conditions in Table 2, entry 4 are defined as conditions A. The arylboronic acid with an electron-donating group $4 \mathbf{c}$ also provided a better yield under conditions B rather than conditions A (Table 3, entries 3 and 4). The desired naphthyloxazole 5aad was obtained in a high yield ( $77 \%$, Table 3 , entry 5$)$. Introduction of a $p$-tolyl group afforded a good yield of $71 \%$ (Table 3, entry 6), whereas reactions of the $o$-tolyl group resulted in moderate yields under both conditions owing to the steric effect (Table 3, entries 7 and 8). The reaction with 3-thienylboronic acid (4g) under conditions B proceeded to give $\mathbf{5 a a g}$ in $68 \%$ yield (Table 3, entries 9 and 10). No product was obtained when $n$-butylboronic acid (4h) was used as an aliphatic boronic acid (Table 3, entry 11). Subsequently, the effect of substituents at the 2-position, which was derived from the carboxylic acids, was tested. Aryl substituents possessing both electron-withdrawing and electron-donating groups proceeded to give the corresponding oxazoles in good yields (Table 3, entries 12 and 13). Aliphatic substituents are innocent in the reaction outcome (Table 3, entries 14 and 15). Suzuki-Miyaura coupling of several intermediates 3ab-3af, which have different substituents at the 4-position, were examined (Table 3, entries 16-20). 
Table 3: Synthesis of various trisubstituted oxazoles.

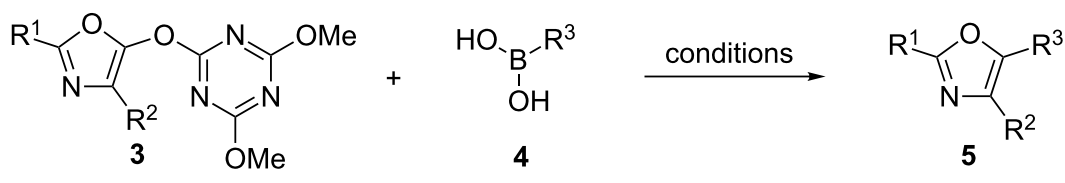

conditions $\mathrm{A}$ :

$\mathrm{NiCl}_{2}$ (dppf) (5 mol \%), LiCl (3 equiv) $\mathrm{K}_{3} \mathrm{PO}_{4}$ (7 equiv), toluene, reflux

conditions B:

$\mathrm{NiCl}_{2}$ (dppf) (5 mol \%), LiCl (3 equiv)

$\mathrm{K}_{3} \mathrm{PO}_{4}$ (7 equiv), dppf ( $\left.5 \mathrm{~mol} \%\right)$

toluene, $110^{\circ} \mathrm{C}$, sealed tube<smiles>CCOC(=O)c1ccc(CC)cc1</smiles>

$4 b$<smiles>COc1ccc(CCCC(C)(C)C)cc1</smiles>

4c<smiles>CCc1ccc2ccccc2c1</smiles>

4d<smiles></smiles>

$4 e$<smiles>CCCCc1ccccc1C</smiles>

$4 f$<smiles>[Y]c1cccs1</smiles>

$4 \mathrm{~g}$
\{. $n-\mathrm{Bu}$

$4 h$

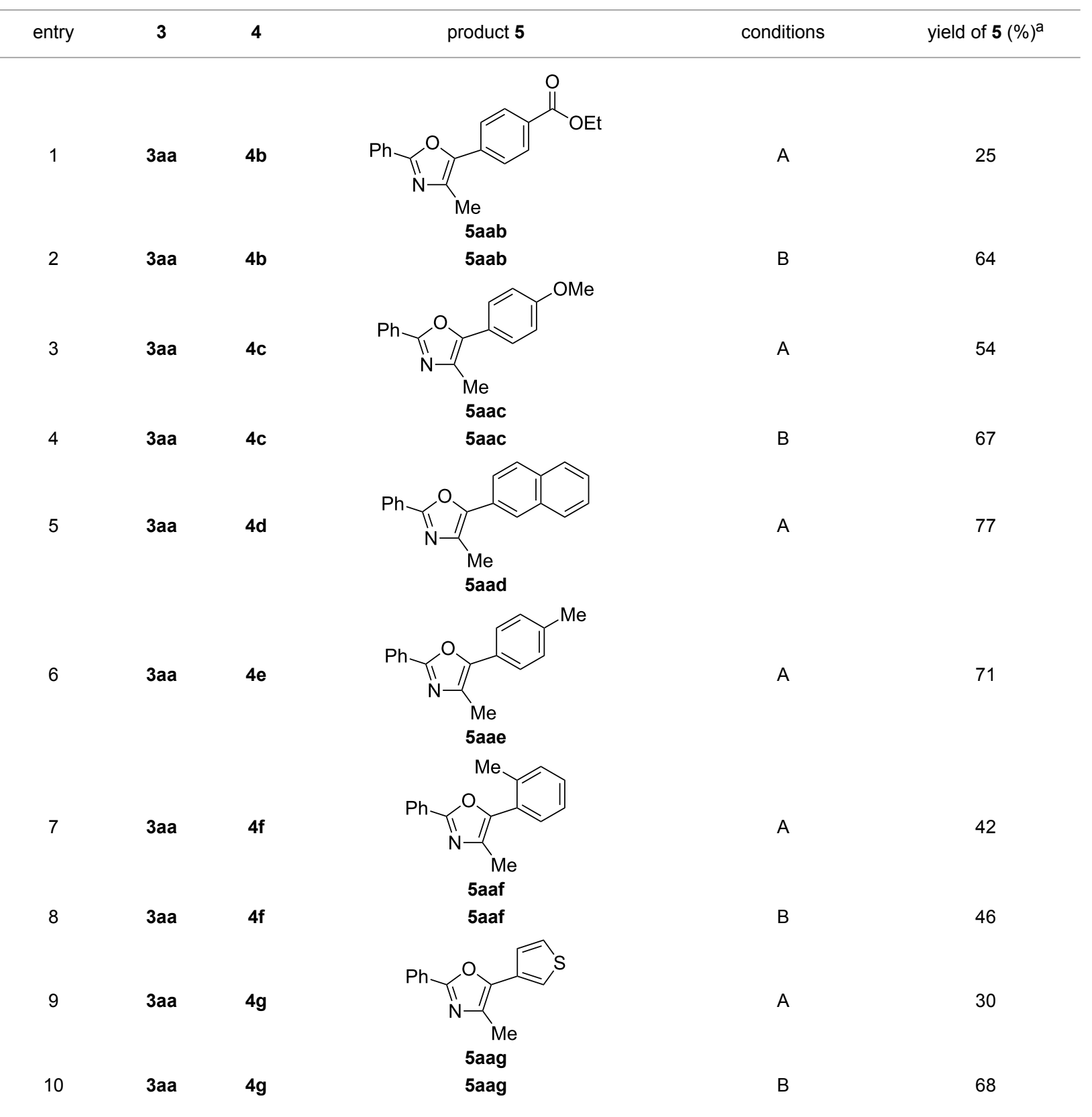


Table 3: Synthesis of various trisubstituted oxazoles. (continued)

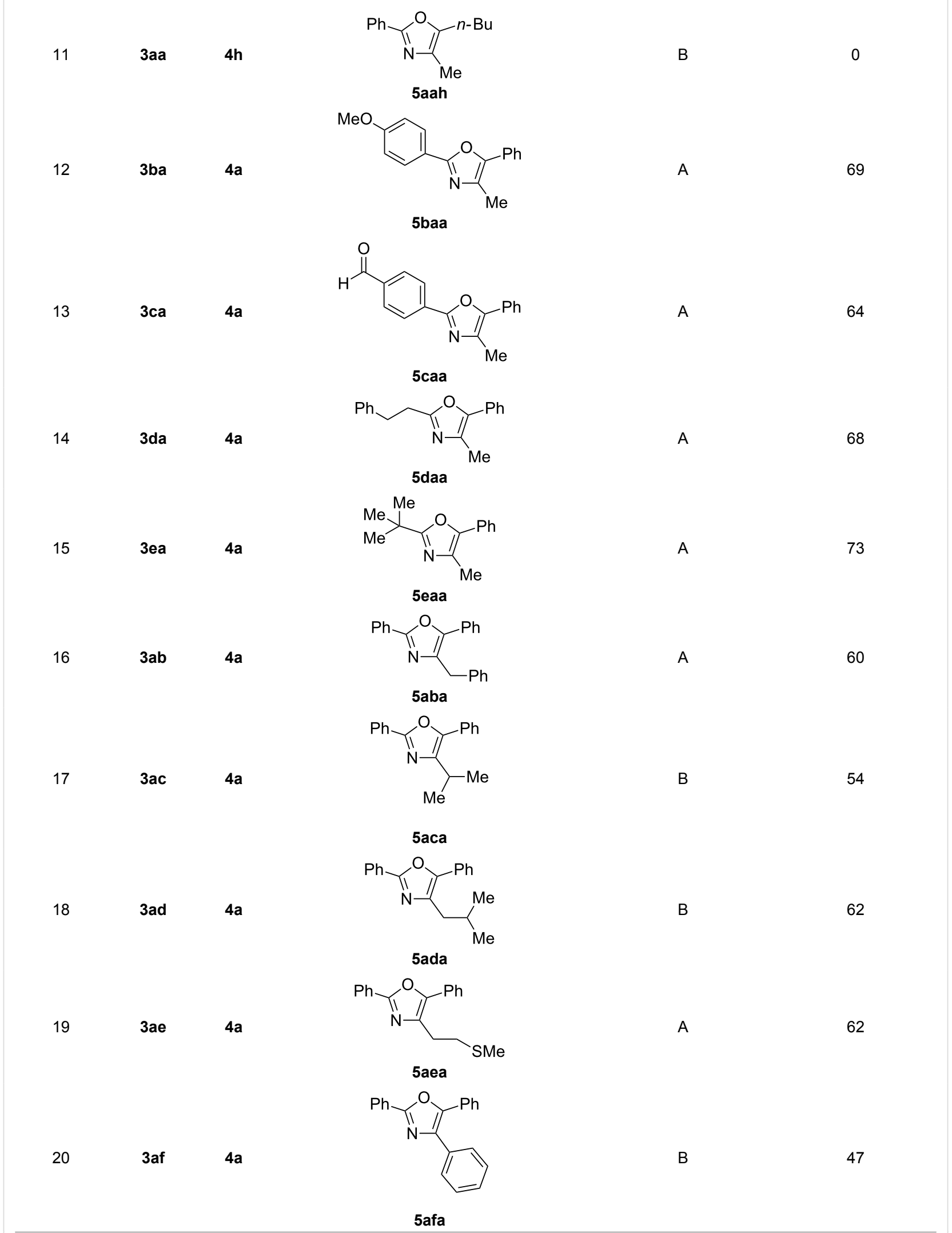

alsolated yield. 
Compared with 3aa, the yields using these compounds were slightly lower, especially in the case of sterically more hindered 3ac and 3af (Table 3, entries 17 and 20). Thus, Suzuki-Miyaura coupling is affected by steric hindrance from the 4-substituent of oxazoles.

It is noteworthy that the synthesis of bis-oxazole intermediate 3fa with highly polar terephthalic acid (1f) and subsequent double coupling reaction with 4 a successfully proceeded to give DMPOPOP (5faa), which is used as a liquid scintillator [38], in a good yield (Scheme 2).

\section{Conclusion}

We have successfully developed a new synthetic method for 2,4,5-trisubstituted oxazoles comprising of carboxylic acids, amino acids, and boronic acids in a one-pot oxazole synthesis with following Ni-catalyzed Suzuki-Miyaura coupling. The combination of various starting materials, which are commercially available, provided the corresponding 2,4,5-trisubstituted oxazoles in good yields. Furthermore, several functionalities, such as ethoxycarbonyl, formyl, and methylsulfanyl groups, which are sensitive to acids, bases, nucleophiles, electrophiles and oxidants, were able to tolerate these reaction conditions (Table 1, entries 3, 9 and Table 3, entries 2, 13 and 19). Therefore, this method is suitable for the synthesis of numerous oxazoles with diverse functionalities.

\section{Supporting Information}

\section{Supporting Information File 1}

General information, Table S1, experimental procedure and characterization data for products, and ${ }^{1} \mathrm{H}$ and ${ }^{13} \mathrm{C}$ NMR spectra.

[http://www.beilstein-journals.org/bjoc/content/ supplementary/1860-5397-13-146-S1.pdf]

\section{Acknowledgements}

This work is financially supported by JSPS KAKENHI Grant Numbers 26293003, 25460012 and Teijin Pharma Award in Synthetic Organic Chemistry, Japan.

\section{References}

1. Turchi, I. J.; Dewar, M. J. S. Chem. Rev. 1975, 75, 389-437. doi:10.1021/cr60296a002

2. Wipf, P. Chem. Rev. 1995, 95, 2115-2134. doi:10.1021/cr00038a013

3. Robinson, R. J. Chem. Soc. 1909, 95, 2167-2174. doi:10.1039/CT9099502167

4. Gabriel, S. Ber. Dtsch. Chem. Ges. 1910, 43, 134-138. doi:10.1002/cber.19100430117

5. Davidson, D.; Weiss, M.; Jelling, M. J. Org. Chem. 1937, 2, 328-334. doi:10.1021/jo01227a005

6. Wipf, P.; Aoyama, Y.; Benedum, T. E. Org. Lett. 2004, 6, 3593-3595. doi:10.1021/ol0485058

7. Patil, P. C.; Luzzio, F. A.; Demuth, D. R. Tetrahedron Lett. 2015, 56, 3039-3041. doi:10.1016/j.tetlet.2014.11.014

8. Bailey, J. L.; Sudini, R. R. Tetrahedron Lett. 2014, 55, 3674-3677. doi:10.1016/j.tetlet.2014.05.002

9. Saito, A.; Taniguchi, A.; Kambara, Y.; Hanzawa, Y. Org. Lett. 2013, 15 2672-2675. doi:10.1021/ol4009816

10. Liu, D.; Yu, J.; Cheng, J. Tetrahedron 2014, 70, 1149-1153. doi:10.1016/j.tet.2013.12.077

11. Zhang, L.; Zhao, X. Org. Lett. 2015, 17, 184-186. doi:10.1021/ol5030986

12. Yoshizumi, T.; Satoh, T.; Hirano, K.; Matsuo, D.; Orita, A.; Otera, J.; Miura, M. Tetrahedron Lett. 2009, 50, 3273-3276. doi:10.1016/j.tetlet.2009.02.039

13. Théveau, L.; Verrier, C.; Lassalas, P.; Martin, T.; Dupas, G.; Querolle, O.; Van Hijfte, L.; Marsais, F.; Hoarau, C. Chem. - Eur. J. 2011, 17, 14450-14463. doi:10.1002/chem.201101615

14. Haas, D.; Mosrin, M.; Knochel, P. Org. Lett. 2013, 15, 6162-6165. doi:10.1021/ol403019c

15. Amaike, K.; Muto, K.; Yamaguchi, J.; Itami, K. J. Am. Chem. Soc. 2012, 134, 13573-13576. doi:10.1021/ja306062c

16. Hodgetts, K. J.; Kershaw, M. T. Org. Lett. 2002, 4, 2905-2907. doi:10.1021/ol0262800

17. Shaw, A. Y.; Xu, Z.; Hulme, C. Tetrahedron Lett. 2012, 53, 1998-2000. doi:10.1016/j.tetlet.2012.02.030<smiles>O=C(O)c1ccc(C(=O)O)cc1</smiles>

$1 f$ (i) DMT-MM (2.1 equiv) NMM ( 0.2 equiv) 1,4-dioxane/ $\mathrm{H}_{2} \mathrm{O}(2: 1)$

(ii) alanine (2.2 equiv) $\mathrm{NaOH}$ (2.2 equiv)

(iii) DMT-MM (6.0 equiv) NMM (4.0 equiv) $65 \%$<smiles></smiles>

4a (8.0 equiv), $\mathrm{NiCl}_{2}$ (dppf) (10 mol \%)

$\mathrm{LiCl}$ (3.0 equiv), $\mathrm{K}_{3} \mathrm{PO}_{4}$ (14 equiv) dppf (5 mol \%)

toluene, $110^{\circ} \mathrm{C}$, sealed tube $6 \mathrm{~h}, 63 \%$<smiles>Cc1nc(-c2ccc(-c3nc(C)c(-c4ccccc4)o3)cc2)oc1-c1ccccc1</smiles>

Scheme 2: Synthesis of DMPOPOP. 
18. Querard, P.; Girard, S. A.; Uhlig, N.; Li, C.-J. Chem. Sci. 2015, 6, 7332-7335. doi:10.1039/C5SC02933C

19. Kunishima, M.; Kawachi, C.; Iwasaki, F.; Terao, K.; Tani, S. Tetrahedron Lett. 1999, 40, 5327-5330. doi:10.1016/S0040-4039(99)00968-5

20. Kunishima, M.; Kawachi, C.; Monta, J.; Terao, K.; Iwasaki, F.; Tani, S. Tetrahedron 1999, 55, 13159-13170. doi:10.1016/S0040-4020(99)00809-1

21. Kunishima, M.; Kawachi, C.; Hioki, K.; Terao, K.; Tani, S. Tetrahedron 2001, 57, 1551-1558. doi:10.1016/S0040-4020(00)01137-6

22. Kitamura, M.; Kunishima, M.

4-(4,6-Dimethoxy-1,3,5-triazin-2-yl)-4-methylmorpholinium chloride. In e-EROS (Encyclopedia of Reagents for Organic Synthesis) [Online]; Crich, D.; Charette, A. B.; Fuchs, P. L., Eds.; John Wiley \& Sons, Ltd: West Sussex, 2013.

23. Fujita, H.; Kunishima, M. Chem. Pharm. Bull. 2012, 60, 907-912. doi:10.1248/cpb.c12-00291

24. Li, X.-J.; Zhang, J.-L.; Geng, Y.; Jin, Z. J. Org. Chem. 2013, 78, 5078-5084. doi:10.1021/j04005537

25. Iranpoor, N.; Panahi, F. Adv. Synth. Catal. 2014, 356, 3067-3073. doi:10.1002/adsc. 201400460

See for amination

26. Iranpoor, N.; Panahi, F. Org. Lett. 2015, 17, 214-217. doi:10.1021/ol503560e See for reduction.

27. Yu, B.; Sun, H.; Xie, Z.; Zhang, G.; Xu, L.-W.; Zhang, W.; Gao, Z. Org. Lett. 2015, 17, 3298-3301. doi:10.1021/acs.orglett.5b01466 See for Sonogashira coupling.

28. Yamada, K.; Fujita, H.; Kunishima, M. Org. Lett. 2012, 14, 5026-5029. doi:10.1021/ol302222p

We have developed acid-catalyzed triazine-type alkylating reagents, in which triazinyloxy group works as a leaving group. See also refs. [29-33].

29. Yamada, K.; Yoshida, S.; Fujita, H.; Kitamura, M.; Kunishima, M. Eur. J. Org. Chem. 2015, 36, 7997-8002. doi:10.1002/ejoc.201501172

30. Fujita, H.; Hayakawa, N.; Kunishima, M. J. Org. Chem. 2015, 80, 11200-11205. doi:10.1021/acs.joc.5b02059

31. Yamada, K.; Fujita, H.; Kitamura, M.; Kunishima, M. Synthesis 2013, 45, 2989-2997. doi:10.1055/s-0033-1339713

32. Yamada, K.; Hayakawa, N.; Fujita, H.; Kitamura, M.; Kunishima, M. Eur. J. Org. Chem. 2016, 4093-4098. doi:10.1002/ejoc.201600663

33. Yamada, K.; Hayakawa, N.; Fujita, H.; Kitamura, M.; Kunishima, M. Chem. Pharm. Bull. 2017, 65, 112-115. doi:10.1248/cpb.c16-00744

34. Scott, W. J.; Crisp, G. T.; Stille, J. K. J. Am. Chem. Soc. 1984, 106, 4630-4632. doi:10.1021/ja00328a063

35. Yamamoto, Y.; Takizawa, M.; Yu, X.-Q.; Miyaura, N. Angew. Chem., Int. Ed. 2008, 47, 928-931. doi:10.1002/anie.200704162

36. Saito, S.; Oh-tani, S.; Miyaura, N. J. Org. Chem. 1997, 62, 8024-8030. doi:10.1021/jo9707848

37. The reaction of $\mathbf{3} \mathbf{a}$ and $\mathbf{4 a}$ under conditions $\mathrm{B}$ afforded a comparable yield (65\%, Table S1, entry 16$)$.

38. Nemchenok, I. B.; Babin, V. I.; Brudanin, V. B.; Kochetov, O. I.; Timkin, V. V. Phys. Part. Nucl. Lett. 2011, 8, 129-135. doi:10.1134/S1547477111020099

\section{License and Terms}

This is an Open Access article under the terms of the Creative Commons Attribution License

(http://creativecommons.org/licenses/by/4.0), which permits unrestricted use, distribution, and reproduction in any medium, provided the original work is properly cited.

The license is subject to the Beilstein Journal of Organic Chemistry terms and conditions:

(http://www.beilstein-journals.org/bjoc)

The definitive version of this article is the electronic one which can be found at:

doi:10.3762/bjoc. 13.146 